\title{
BRIDELIA SCANDENS WILD. A NEW SOURCE FOR PODOPHYLLOTOXIN PRODUCTION IN VITRO BY FEEDING CONIFERYL ALCOHOL
}

\author{
RAVIKUMAR S, KRISHNA V, AJITH S
}

Department of PG Studies and Research in Biotechnology Kuvempu University, Shankaraghatta, Shivamogga, Karnataka, India. Email: krishnabiotech2003@gmail.com

Received: 16 July 2020, Revised and Accepted: 19 August 2020

\section{ABSTRACT}

Objective: In the present study, a new method for the production of anticancerous compound podophyllotoxin (PTOX) was developed for Bridelia scandens Wild. by feeding coniferyl alcohol.

Methods: The production of anticancerous compound PTOX through leaf explant derived calli of B. scandens. Murashige and Skoog (MS) medium fortified with $0.5 \mathrm{mg} / \mathrm{l}$ 6-Benzylaminopurine (BAP) and $0.5 \mathrm{mg} / \mathrm{l}$ 2,4-D (2,4-Dichlorophenoxyacetic acid) induced luxuriant mass of callus growth. Suspension culture was initiated by sterile MS media fortified with $0.1-1.0 \mathrm{mg} / \mathrm{l} \mathrm{BAP}$ and $0.1-1.0 \mathrm{mg} / \mathrm{l} 2,4$-D. and growth product was analyzed by the high-pressure liquid chromatography method.

Results: Phytochemical analysis of the B. scandens leaf and leaf calli showed the presence of PTOX at the concentrations of 0.69 and 1.81 , respectively. The callus cell suspension was established with the same callogenic media also it is augmented with 10-70 mg/l of coniferyl alcohol to elicit the biosynthesis of PTOX. Successive cultures of the calli suspension yielded stable production of PTOX of $3.91 \mathrm{mg} / \mathrm{g}$ dry cell weight at $50 \mathrm{mg} / \mathrm{l}$ coniferyl alcohol in the media. The biosynthesis of PTOX was ideal when plant cells were cultivated in the dark with an agitation speed of 100 rpm.

Conclusion: The growth and production of PTOX were found to be better with glucose than with sucrose as the medium carbon source. The harvesting of the secondary metabolite from the in vitro grown leaf calli of B. scandens is a better way to stop the exploitation of medicinal plants.

Keywords: Bridelia scandens, Podophyllotoxin, Coniferyl alcohol, Secondary metabolite.

(C) 2020 The Authors. Published by Innovare Academic Sciences Pvt Ltd. This is an open access article under the CC BY license (http://creativecommons. org/licenses/by/4. 0/) DOI: http://dx.doi.org/10.22159/ajpcr.2020.v13i11.39073

\section{INTRODUCTION}

Many clinically useful prescription drugs have originated from traditional medicinal plants. Since there are many traditional medicinal plants widely used by society, it is worth subjecting these plants to investigate for the discovery of drugs with anticipation of obtaining new bioactive substances [1].

The acquisition of secondary metabolites from natural or field-cultivated plants by extraction depends greatly on the growing environment, which significantly affects the quality and quantity of chemical compounds. Plant tissue culture technology offers an alternative route for both plant propagation and secondary metabolite production. The method allows the growth of plant materials that otherwise would be difficult to grow in nature because of geographic, climatic, or seasonal restrictions. From the plant materials, the production of secondary metabolites can also be manipulated in vitro, which can lead to overproduction of compounds of interest, or the production of chemicals not originally found in native plants [1].

Secondary metabolites from the plant source serve as medicines, cosmetics, food additives, and nutraceuticals. In vitro, plant cell culture is an alternative to the high-level production of several economically important secondary metabolites. Plants containing podophyllotoxin (PTOX) analogs have been used as folk medicine in traditional medicines for use in the treatment of cancer, cold, cough, wounds, fever, ulcers, tumors, etc. [2]. The phenylpropanoid derived lignan PTOX is used as a starting compound for the synthesis of etoposide (VP-16-213), teniposide (VM-26), and etophos, which are used in the treatment of specific types of cancers such as testicular, ovary, and breast and lung cancer. PTOX is also used as a precursor for new derivative CPH-82 (reumacon) being tested in Europe in Phase III clinical trials for arthritis [3], and also was found to be the most active component in inhibiting the replication of measles and herpes simplex type I virus [4].

PTOX is included in many pharmacopeias and used as an antiviral agent in the treatment of condyloma acuminatum caused by human papillomavirus (HPV) [5] and other venereal and perianal warts [6-10]. It is also effective in the treatment of anogenital warts in children and against molluscum contagiosum that is generally a self-limiting benign skin disease that affects mostly children, young adults, and HIV patients [11].

Antitumor activity is another outstanding property of PTOX. It is effective in the treatment of Wilms tumors, different types of genital tumors (carcinoma verrucosus) and non-Hodgkin and other lymphomas [7], and lung cancer [12,13].

In vitro, production of PTOX is important to pharmaceutical industries in a predictable manner at lower costs. It also opens the windows to improve its quality further and to extend its application as natural medicines. The production of PTOX through plant cell culture in vitro has been accomplished in several plant species: Podophyllum hexandrum [14] and Linum linearifolium [15]. In the present study, PTOX has been isolated from the leaf calli of Bridelia Scandens; further, the production of PTOX through their in vitro culture has great relevance to industrial application.

B. scandens is an important medicinal plant of the Western Ghats region belongs to the family Euphorbiaceae, which is greatly used in herbal drugs manufacturing, B. scandens has many medicinal properties such as antioxidant, anti-inflammatory, hematopoiesis effects, and used for the treatment of cancer. It is distributed in the warm regions of Southeast Asia and also in Western peninsular India, especially in deciduous to semi-evergreen forests of Maharashtra, 
Kerala, and Karnataka states (http://www.indiabiodiversity.org). The plant having medicinal possesses complex phytochemicals. The investigation of $B$. scandens plant revealed their high potential to produce a wide array of bioactive secondary metabolites. There are no reports on the isolation of PTOX from this plant species, and so far the plant is not studied in vitro. Hence, in this paper, we reported the in vitro production of PTOX from the leaf calli cell lines of $B$. scandens.

\section{METHODS}

Plant material and callus culture

Meristematic leaf explants of $B$. scandens were collected from the Bhadra Wild Life Sanctuary of the Western Ghats $(1 \mathrm{~km}$ from Kuvempu University) and were identified by Prof. V Krishna, professor and taxonomist, Dept. of Biotechnology, Kuvempu University. The leaves were cleaned with deionized water, sterilized with $5 \%$ tween-20, $0.2 \%$ mercuric chloride, followed by sterilized distilled water wash, and then $1 \mathrm{~cm}$ leaf discs were aseptically inoculated on to Murashige and Skoog (MS) semi-solid media. The leaf explants of B. scandens proliferated into callus mass on MS media fortified with $0.5 \mathrm{mg} / \mathrm{l}$ 6-Benzylaminopurine (BAP) and $0.5 \mathrm{mg} / \mathrm{l} \mathrm{2}$, 4-D subculturing of the calli on to the same media-induced luxuriant proliferation of the fleshy callus mass.

\section{Initiation of suspension culture}

Suspension cultures were established by transferring approximately $500 \mathrm{mg}$ callus into $250 \mathrm{ml}$ conical flasks containing $150 \mathrm{ml}$ sterile MS media fortified with $0.1-1.0 \mathrm{mg} / \mathrm{l} \mathrm{BAP}$ and $0.1-1.0 \mathrm{mg} / \mathrm{l} 2$, 4-D. They were incubated $24^{\circ} \mathrm{C}$ on a rotary shaker at $125 \mathrm{rpm}$. The suspension cultures were subcultured after every 3 weeks by transferring $50 \mathrm{ml}$ of callus suspension, which contain fresh calli cells to fresh medium at an interval of 30 days.

\section{Effect of coniferyl alcohol PTOX production}

Different concentrations of coniferyl alcohol (10-70 mg/l) were used to study their effect on the growth of calli and PTOX production in $B$. scandens callus cell lines, all the experiments were carried out aseptically in $150 \mathrm{ml}$ MS media+glucose $(35 \mathrm{~g} / \mathrm{l})$ medium in $250 \mathrm{ml}$ conical flasks. The cultures were grown on an incubator shaker at $100 \mathrm{r} \mathrm{pm}$ at $24 \pm 2^{\circ} \mathrm{C}$ under $12 \mathrm{~h}$ darkness for 30 days, after which they were analyzed for growth and PTOX. The data represent the mean of ten cultures, the analysis of variance (ANOVA) was performed using ezANOVA (version 0.98) software and Microsoft Excel to determine the mean and standard deviation.

\section{Analysis of growth and the product}

The calli were harvested after 40 days of incubation. The samples were centrifuged at $4000 \mathrm{rpm}$ for $15 \mathrm{~min}$ and the supernatant was collected separately, and the precipitated callus cells were washed with distilled water and centrifuged again to obtain the cells, which were then dried at $60^{\circ} \mathrm{C}$ for $16 \mathrm{~h}$ to determine the dry cell weight (DW). Estimation of PTOX was performed by extracting, $1 \mathrm{~g}$ of dried cell mass was in methanol, as described by Heyenga et al. [16]. High-pressure liquid chromatography (HPLC) method was used for determining the PTOX in calli sample of B. scandens using a NovaPak C18 column $(250-4.6 \mathrm{~mm})$ in an HPLC system (Waters, USA) connected to a ultraviolet (UV)-detector (Waters, model 440 UV absorbance detector) [15].

High-resolution liquid chromatograph mass spectrometer (HRLCMS) analysis of leaf calli sample

The bioactive components of $B$. scandens leaf calli sample were analyzed by HR-LCMS G6550A system (Agilent Technologies). The method used for chromatography was $30 \mathrm{~min} \pm$ ESI 10032014_MSMS.m. The gas temperature used for analysis was $250^{\circ} \mathrm{C}$. The theoretical mass of the protonated compound was used for identification. HR-LCMS analysis was performed at Sophisticated Analytical Instrument Facility, Indian Institute of Technology, Mumbai, India. The compound was identified by comparison with their retention time (RT) and mass with stored Metlin library available with IIT, Bombay.

\section{RESULTS}

\section{Callus culture}

Leaf explants of B. scandens which are inoculated aseptically are started proliferating into callus mass after 14-15 days on MS media fortified with $0.5 \mathrm{mg} / \mathrm{l} \mathrm{BAP}$ and $0.5 \mathrm{mg} / \mathrm{l} \mathrm{2,} \mathrm{4-D.} \mathrm{Callus} \mathrm{induction} \mathrm{was} \mathrm{noticed}$ from the cut end of the lamina and the dorsal vein of the explants after 3 to 4 weeks (Fig. 1). After 60 days, the callus is well developed and ready for the subculture. Subculturing of the calli on the same MS media, induced luxuriant proliferation of the fleshy callus mass which can be seen in Fig. 1.

\section{Initiation of suspension culture}

Initiation of suspension culture from the callus was difficult due to severe browning of the culture broth, clumping of cells, and drop in $\mathrm{pH}$ which affected the cell viability. To overcome these problems, several media formulations along with various combinations of growth hormones were used to initiate the suspension cultures. Fresh fleshy callus grown 45 days on MS solid medium were used for the primary inoculant and inoculated into liquid MS medium with similar compositions and concentrations of nutrients and growth regulators as mentioned previously, MS medium was suitable for callus culture. Cells cultivated in MS liquid medium were smoothly clustered with each other in the MS liquid medium, cells were better dispersive and maintained good status as bright yellow cells aggregates with high growth rates (Fig. 1). Thus, the basic MS medium was optimal nutrient formulation for $B$. scandens cell suspension cultures.

\section{Effect of glucose}

Among the nutritional factors, sugar plays a significant role in controlling secondary metabolism. Commonly, sucrose is used in the culture media, but glucose and fructose have also been employed. In PTOX cell cultures, glucose was found to be more suitable than sucrose for both cell growth and PTOX production [17]. The effect of glucose on $B$. scandens cell cultures was, therefore, investigated at different glucose concentrations $(20-50 \mathrm{~g} / \mathrm{l})$. Maximum cell growth was observed at $35 \mathrm{~g} / \mathrm{l}$, followed by $\mathrm{pH}$ 5.8. An increase in glucose level showed a decrease in cell growth and viability (Table 1).
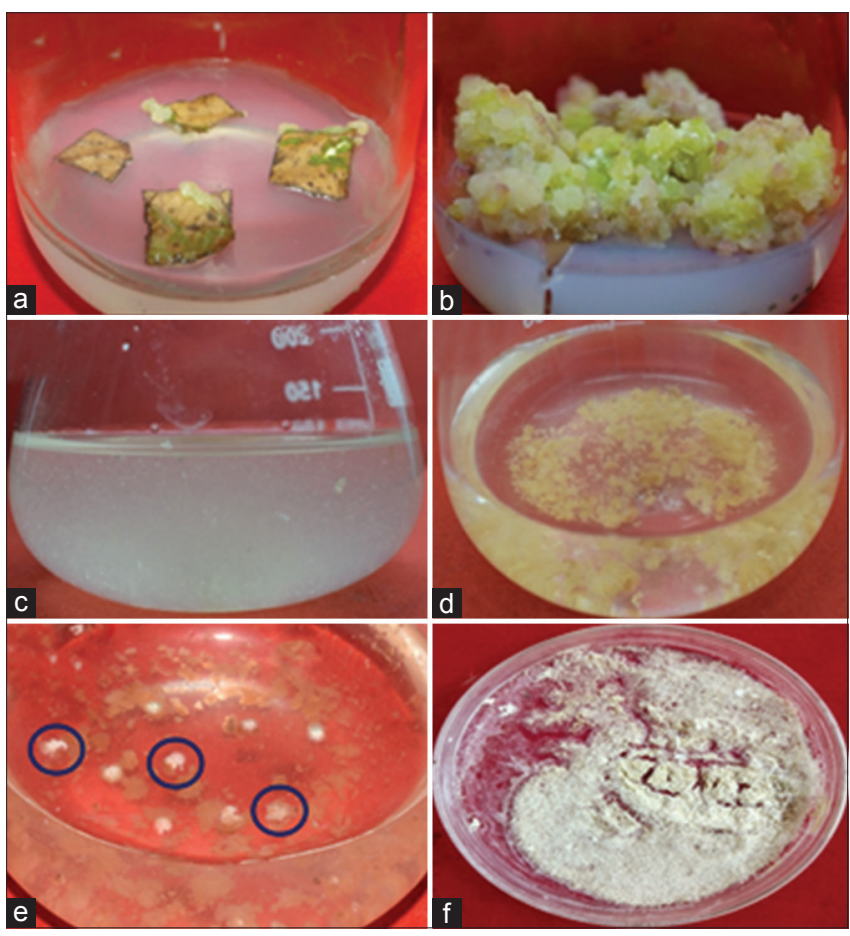

Fig. 1: a-Leaf inoculation for callus culture, b-Mass culture of callus, c-Suspension culture with coniferyl alcohol, $d$-Increase in callus cell Density, e-White mass-like structure appears on the cell mass, f-Compound produced from suspension culture 
Effect of coniferyl alcohol

The effect of different concentrations of coniferyl alcohol for growth and production of PTOX is shown in Table 2. The production of biomass, as well as PTOX, was maximum in the presence of coniferyl alcohol. The cells proliferate very fast and the turbidity is more when compared to normal culture (Fig. 1).

Therefore, coniferyl alcohol at 10-70 mg/l was used only for the suspension cultures. Coniferyl alcohol has been reported as an effective elicitor for the synthesis of PTOX in suspension cultures of Podophyllum sp. where it caused rapid de novo biosynthesis of large amounts PTOX [18]. The production of PTOX was maximum at $40-50 \mathrm{mg} / \mathrm{l}$ coniferyl alcohol. They, therefore, used it at $50 \mathrm{mg} / \mathrm{l}$ in the medium to optimize the production of PTOX.

\section{HR-LCMS analysis of leaf calli sample}

The results of HR-LCMS for the sample showing compound molecular formula $\mathrm{C}_{22} \mathrm{H}_{22} \mathrm{O}_{8}$ and molecular weight of 414 , as shown in Table 3 and Figs. 2 and 3 chromatogram shows the RT and molecular weight, so these results confirm that compound is PTOX.

\section{DISCUSSION}

Compare to other plant tissue culture media MS medium was the bestsuited for B. scandens cell growth and PTOX production. PTOX with anticancer properties serves as a safe source of the natural compound. Production of PTOX through in vitro strategies has been carried out in several plants such as P. hexandrum [8], Podophyllum peltatum [19], Silybum marianum [20], and L. linearifolium [15]. The documentation of plant species for new sources of PTOX increases PTOX diversity. The production of PTOX of specific nature relies on plant species and their production in vitro has to be addressed and standardized specifically to each species. The present study forecasts $B$. scandens as a new source of PTOX.

The accumulation of PTOX was specific to the type and concentration of plant growth regulators and elicitors. The different concentrations of plant growth regulators tested, a combination of BAP $(0.5 \mathrm{mg} / \mathrm{l})$ and 2,4-
Table 1: Data represent the mean of ten cultures, the cultures were grown in MS medium containing 20-50 g/l glucose sucrose at 125 r.p.m. and $22^{\circ} \mathrm{C}$ under $16 \mathrm{~h}$ dark and $8 \mathrm{~h}$ light

\begin{tabular}{lll}
\hline Glucose and sucrose in grams & \multicolumn{2}{l}{ Dry cell wt $(\mathrm{g} / \mathbf{l}) \pm$ SD $(\mathrm{g})$} \\
\cline { 2 - 3 } & Glucose & Sucrose \\
\hline 20 & $6.43 \pm 0.03$ & $5.49 \pm 0.23$ \\
25 & $6.75 \pm 0.04$ & $6.10 \pm 0.09$ \\
30 & $8.69 \pm 0.09$ & $8.27 \pm 0.19$ \\
35 & $10.75 \pm 0.08$ & $9.69 \pm 0.20$ \\
40 & $9.33 \pm 0.10$ & $9.85 \pm 0.15$ \\
45 & $9.55 \pm 0.17$ & $9.37 \pm 0.14$ \\
50 & $7.35 \pm 0.15$ & $4.26 \pm 0.17$ \\
\hline
\end{tabular}

All the results were expressed as mean \pm SD of ten different trials

Table 2: Data represent the mean of ten cultures, the cultures were grown in MS medium containing $35 \mathrm{~g}$ glucose/1 at 125 r.p.m. and $22^{\circ} \mathrm{C}$ under $16 \mathrm{~h}$ dark and $8 \mathrm{~h}$ light

\begin{tabular}{lll}
\hline Coniferyl alcohol mg/l & $\begin{array}{l}\text { Dry cell } \\
\text { wt } \pm \text { SD }(\mathbf{g})\end{array}$ & $\begin{array}{l}\text { PTOX (mg/g } \\
\text { DW) } \pm \text { SD } \mathbf{~ ( m g ) ~}\end{array}$ \\
\hline 0.0 & $7.56 \pm 0.09$ & $1.81 \pm 0.06$ \\
10 & $7.87 \pm 0.12$ & $2.41 \pm 0.06$ \\
20 & $8.11 \pm 0.07$ & $2.94 \pm 0.06$ \\
30 & $8.81 \pm 0.06$ & $3.01 \pm 0.06$ \\
40 & $9.72 \pm 0.12$ & $3.85 \pm 0.03$ \\
50 & $10.79 \pm 0.12$ & $3.91 \pm 0.06$ \\
60 & $10.65 \pm 0.12$ & $3.11 \pm 0.03$ \\
70 & $10.20 \pm 0.13$ & $3.04 \pm 0.06$ \\
\hline
\end{tabular}

Expressed all the results as mean $\pm \mathrm{SD}$ of ten different trials

Table 3: HR-LCMS results of the sample

\begin{tabular}{|c|c|c|c|c|}
\hline Compound label & $\mathbf{m} / \mathbf{z}$ & RT & Algorithm & Mass \\
\hline Cpd 1: $\mathrm{C}_{22} \mathrm{H}_{22} \mathrm{O}_{8}$ & 397.1272 & 19.977 & Find By Formula & 414.1195 \\
\hline
\end{tabular}

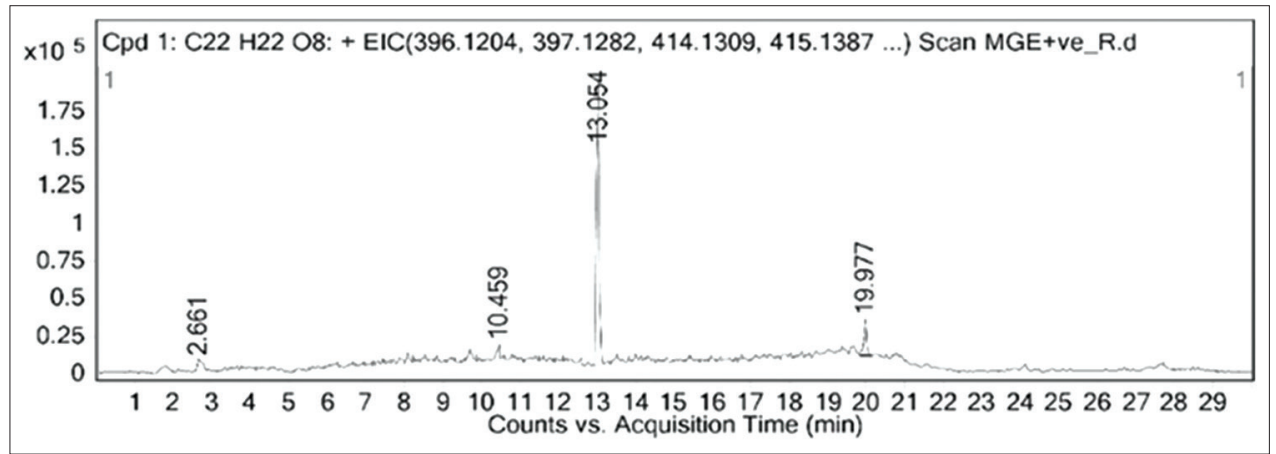

Fig. 2: Chromatogram of the sample

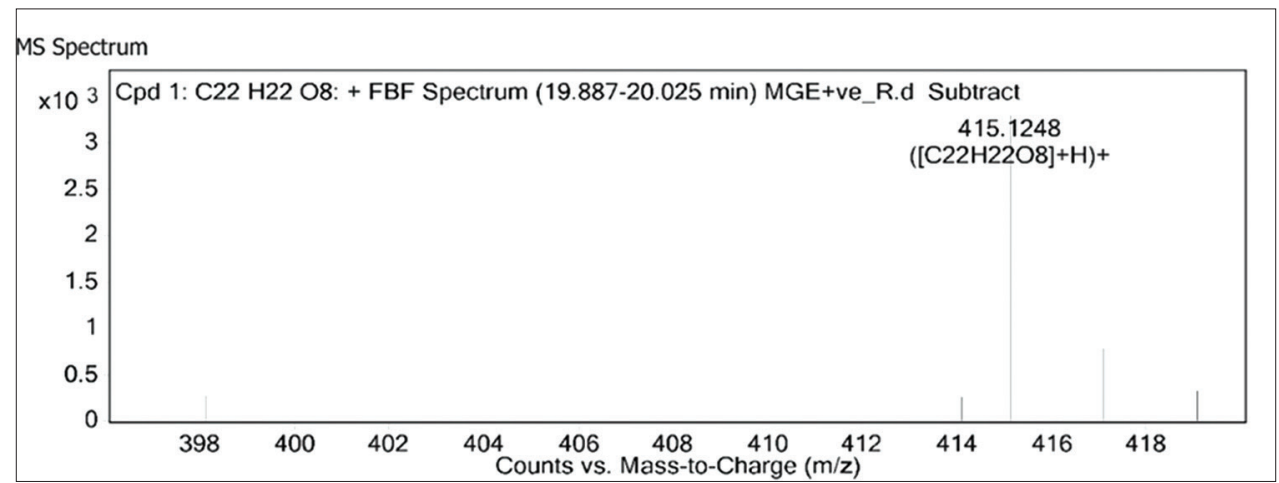

Fig. 3: Mass spectrum of the sample 
D $(0.5 \mathrm{mg} / \mathrm{l})$ facilitated the maximum accumulation of PTOX. As noticed in the culture of $P$. hexandrum by Herman [21] in the present study also, the presence of coniferyl alcohol-induced the enhancement of PTOX. Similarly, the ability of different concentrations of Indole-3-Acetic Acid (IAA), in PTOX production through callus cultures has also been reported in $P$. hexandrum [17] and 2,4-D, IAA and 1-Naphthaleneacetic acid in P. peltatum [22].

The type and levels of carbon sources also induced a significant effect in the production of PTOX in B. scandens. It was noticed that glucose was more effective than sucrose. Sucrose a disaccharide is inverted to monosaccharides (glucose and fructose) by the action of invertase located in the plant cell walls during in vitro culture of plant cells, which vary depending on the plant species. Further, glucose is one of the main products of photosynthesis, supplied directly in the medium is effectively metabolized by the living cells become the reason behind the efficacy of glucose over sucrose. The rate of sucrose inverting capacity of tomato root culture was reported to be the highest on a medium having a $\mathrm{pH}$ of 3.6-4.7 [23]. Moreover, the sugars affect cytodifferentiation by their influence as a cytoplasmic and for vacuolar osmoticum in the cells [24].

The HR-LCMS results for the sample resulted in a compound with the molecular formula of $\mathrm{C}_{22} \mathrm{H}_{22} \mathrm{O}_{8}$ and a molecular weight of 414 . Hence, the results of chromatogram and mass spectrum confirm that the compound is PTOX.

The effect of coniferyl alcohol in the formation of PTOX as in the present study has been accomplished in other plants: P. hexandrum [21], Linum album [25], Hexandrum royle [26], Linum flavum, and P. peltatum [27]. PTOX production Coniferin enhanced the PTOX content to maximal $0.055 \%$. This effect was already seen on day 7 of the growth cycle. The finding that the effect of precursor-feeding on more differentiated cells was less pronounced than in undifferentiated cells, corresponds with observations made for the accumulation of 5-methoxyPTOX in cell suspension cultures of L. flavum [26].

The lignan biosynthesis proceeds through a radical-mediated dimerization reaction of the phenylpropane unit, such as coniferyl alcohol [28]. Coniferyl alcohol originates from coniferin, which loses glucose by specific 3-glucosidase activity in the cultures [29]. Only coniferyl alcohol is commercially available so that only one precursor is used for PTOX biosynthesis. PTOX is an intracellular compound and not excreted into the medium [21] so the mechanical extraction process is followed for the extraction of the compound.

PTOX accumulation in wild plants and plant material obtained by in vitro cultures (cell, callus, tissues, and plantlets) show a different pattern. To date, the greatest production of PTOX has been obtained from the wild plant $P$. hexandrum $43 \mathrm{mg} / \mathrm{g}$ DW [16]; however, this yield diminishes when PTOX is obtained from cell suspension cultures of this species (7.9 mg/g DW) [30]. Similarly, the concentration of PTOX in wild P. peltatum plants is similar to that obtained in cell suspension cultures ( 4.7 and $5.9 \mathrm{mg} / \mathrm{g}$ DW, respectively) $[19,31]$. The accumulation of PTOX in L. album has been reported to be higher in cell suspension cultures (8 mg/g DW) [32]. However, under our conditions, the optimum yield obtained for the B. scandens $(3.91 \mathrm{mg} / \mathrm{g} \mathrm{DW}$ ) is similar to that reported in 2008 by Baldi [33] in L. album, which is 90 times higher than that obtained from wild plants. The PTOX yield in the present study was favorable compared to that reported in other plants. The present study prospects B. scandens as a promising new source of PTOX and its production in in vitro method.

\section{CONCLUSION}

The growth and production of PTOX were found to be better with glucose than with sucrose as the medium carbon source. Due to unscientific overexploitation, many of the medicinal plants are becoming endangered. The harvesting of the secondary metabolite from the in vitro grown leaf calli of $B$. scandens is a better way to stop the exploitation of medicinal plants.

\section{ACKNOWLEDGMENT}

The authors are thankful to DBT, New Delhi, India, for providing financial support through the DBT- BUILDER program (Order No. BT/ PR9128/ INF/22/190/2013, Dated: 30/06/2015) and the Kuvempu University administrative authority for offering the facility to carry out the work.

\section{CONFLICTS OF INTEREST}

The authors declare they have no conflicts of interest.

\section{AUTHORS' CONTRIBUTIONS}

Mr. Ravi Kumar S experimented and performed the computations like statist statistical analysis, Prof. V. Krishna contributed to designing and supervision of the work along with drafting the article. Ravi Kumar S wrote the manuscript with support from Prof. V. Krishna and Mr. Ajith S.

\section{AUTHORS FUNDING}

The authors are thankful to DBT, New Delhi, India, for providing financial support through DBT- BUILDER program (Order No. BT/ PR9128/ INF/22/190/2013, Dated: 30/06/2015)

\section{REFERENCES}

1. Abdoul-Latif FM, Osman DA, Fourreh AE, Hassan-Abdallah A, Merito A, Hassan S, et al. Candidate medicinal plant species of Djiboutian pharmacopeia for testing pharmacological activities on common microbial diseases. Int J Pharm Pharm Sci 2016;8:78-84.

2. Samant SS, Pant S, Singh M, Lal M, Singh A, Sharma A. Medicinal plants in Himachal Pradesh, Northwestern Himalaya, India. Int J Biodivers Sci Manag 2007;3:234-51.

3. Carlström K, Hedin PJ, Jönsson L, Lerndal T, Lien J, Weitoft T. Endocrine effects of the podophyllotoxin derivative drug $\mathrm{CPH} 82$ (Reumacon) in patients with rheumatoid arthritis. Scand J Rheumatol 2000;29:89-94

4. Bedows E, Hatfield GM. An Investigation of the antiviral activity of Podophyllum peltatum. J Nat Prod 1982;45:725-9.

5. Syed TA, Cheema KM, Khayyami M, Ahmad SA, Ahmad SH, Ahmad S, et al. Human leukocyte interferon-alpha versus podophyllotoxin in cream for the treatment of genital warts in males. Dermatology 1995; 191:129-32.

6. Lassus A. Comparison of podophyllotoxin and podophyllin in treatment of genital warts. Lancet 1987;330:512-3.

7. Ayres DC, Loike JD. Lignans: Chemical, Biological, and Clinical Properties. England: Cambridge University Press; 1990.

8. Wantke F, Fleischl G, Götz M, Jarisch R. Topical podophyllotoxin in psoriasis vulgaris. Dermatology 1993;186:79.

9. Beutner KR. Podophyllotoxin in the Treatment of Genital Warts. Vol. 24. Basel, Switzerland: Karger Publishers; 1996.

10. Wilson J. Treatment of genital warts-What's the evidence? Int J STD AIDS 2002; 13:216-20.

11. Markos AR. The successful treatment of molluscum contagiosum with podophyllotoxin $(0.5 \%)$ self-application. Int J STD AIDS 2001;12:833.

12. Utsugi T, Shibata J, Sugimoto Y, Aoyagi K, Wierzba K, Kobunai T. Antitumor activity of a novel podophyllotoxin derivative (TOP53) against lung cancer and lung metastatic cancer. Cancer Res 1996;56:2809-14.

13. Subrahmanyam D, Renuka B, Rao CV, Sagar PS, Deevi DS, Babu JM. Novel D-ring analogues of podophyllotoxin as potent anti-cancer agents. Bioorg Med Chem Lett 1998;8:1391-96.

14. Giri A, Narasu ML. Production of podophyllotoxin from Podophyllum hexandrum: A potential natural product for clinically useful anticancer drugs. Cytotechnology 2000;34:17-26.

15. Ionkova I, Antonova I, Momekov G, Fuss E. Production of podophyllotoxin in Linum linearifolium in vitro cultures. Pharmacogn Mag 2010;6:180-5

16. Heyenga AG, Lucas J, Dewick P. Production of tumour-inhibitory lignans in callus cultures of Podophyllum hexandrum. Plant Cell Rep 1990;9:382-5

17. Chattopadhyay S, Srivastava AK, Bhojwani SS, Bisaria VS. Production of podophyllotoxin by plant cell cultures of Podophyllum hexandrum in bioreactor. J Biosci Bioeng 2002;93:215-20.

18. Ardalani H, Avan A, Ghayour-Mobarhan M. Podophyllotoxin: A novel 
potential natural anticancer agent. Avicenna J Phytomed 2017;7:285-94.

19. Anbazhagan VR, Ahn CH, Harada E, Kim YS, Choi YE. Podophyllotoxin production via cell and adventitious root cultures of Podophyllum peltatum. In Vitro Cell Dev Biol Plant 2008;44:494-501.

20. Tumova L, Gallova K, Rimakova J. Silybum marianum in vitro. Ceska Slov Farm 2004;53:135-40.

21. Woerdenbag HJ, van Uden W, Frijlink HW, Lerk CF, Pras N, Malingre TM. Increased podophyllotoxin production in Podophyllum hexandrum cell suspension cultures after feeding coniferyl alcohol as a $\beta$-cyclodextrin complex. Plant Cell Rep 1990;9:97-100.

22. Kadkade P. Growth and podophyllotoxin production in callus tissues of Podophyllum peltatum. Plant Sci Lett 1982;25:107-15.

23. George EF, Hall MA, De Klerk GJ. The components of plant tissue culture media II: Organic additions, osmotic and $\mathrm{pH}$ effects, and support systems. In: Plant Propagation by Tissue Culture. Dordrecht: Springer Netherlands; 2008.

24. Lila MA. Anthocyanins and human health: An in vitro investigative approach. J Biomed Biotechnol 2004;5:306-13.

25. Smollny T, Wichers H, Kalenberg S, Shahsavari A, Petersen M, Alfermann AW. Accumulation of podophyllotoxin and related lignans in cell suspension cultures of Linum album. Phytochemistry 1998;48:975-9.

26. van Uden W, Pras N, Malingré TM. On the improvement of the podophyllotoxin production by phenylpropanoid precursor feeding to cell cultures of Podophyllum hexandrum Royle. Plant Cell Tissue Organ Cult 1990;23:217-24

27. Xia ZQ, Costa MA, Proctor J, Davin LB, Lewis NG. Dirigent-mediated podophyllotoxin biosynthesis in Linum flavum and Podophyllum peltatum. Phytochemistry 2000;55:537-49.

28. Pelter A. Lignans: Some properties and syntheses. Recent Adv Phytochem 1986;20:201-41.

29. Freudenberg K. Lignin: Its constitution and formation from p-hydroxycinnamyl alcohols: Lignin is duplicated by dehydrogenation of these alcohols; intermediates explain formation and structure. Science 1965;148:595-600

30. Ahmad R, Sharma VK, Rai AK, Shivananda RD, Shivananda BG. Production of lignans in callus culture of Podophyllum hexandrum. Trop J Pharm Res 2007;6:803-8.

31. Bedir E, Khan I, Moraes RM. Bioprospecting for podophyllotoxin. In: Janick J, Whipkey A, editors. Trends in New Crops and New Uses. Alexandria, VA, USA: ASHS Press; 2002. p. 545-9.

32. Wink M, Alfermann AW, Franke R, Wetterauer B, Distl M, Windhövel J. Sustainable bioproduction of phytochemicals by plant in vitro cultures: Anticancer agents. Plant Genet Resour 2005;3:90-100.

33. Baldi A, Srivastava AK, Bisaria VS. Improved podophyllotoxin production by transformed cultures of Linum album. Biotechnol J 2008;3:1256-63. 